\title{
Hypoxia-Inducible Factor-1a Is Involved in the Attenuation of Experimentally Induced Rat Glomerulonephritis
}

\author{
Yoshihiro Kudo ${ }^{a}$ Yoshihiko Kakinuma $^{b}$ Yasukiyo Mori ${ }^{\mathrm{e}}$ \\ Norihito Morimoto $^{a}$ Takashi Karashimac Mutsuo Furihatad \\ Takayuki Sato $^{b}$ Taro Shuin $^{c}$ Tetsuro Sugiura ${ }^{a}$ \\ Departments of a Laboratory Medicine, b Cardiovascular Control, c Urology and d Tumor Pathology, \\ Kochi Medical School, Kochi, and eThe Second Department of Internal Medicine, Kansai Medical University, \\ Osaka, Japan
}

\section{Key Words}

Glomerulonephritis · Habu snake venom •

Angiotensin II - Hypoxia-inducible factor- $1 \alpha$

\begin{abstract}
Background/Aim: Among various kidney disease models, there are few rat glomerulonephritis (GN) models that develop in a short time, and with mainly glomerular lesions. Hypoxia-inducible factor (HIF)- $1 \alpha$ is a transcriptional factor that induces genes supporting cell survival, but the involvement of HIF- $1 \alpha$ in attenuating the progression of $\mathrm{GN}$ remains to be elucidated. We developed a new model of rat GN by coadministration of angiotensin II (AII) with Habu snake venom (HV) and investigated whether HIF-1 $\alpha$ is involved in renal protection. Methods: Male Wistar rats were unilaterally nephrectomized on day 1, and divided into 4 groups on day $0 ; \mathrm{N}$ group (no treatment), HV group, A group (AII), and H+A group (HV and AII). To preinduce HIF-1 $\alpha$, cobalt chloride $\left(\mathrm{CoCl}_{2}\right)$ was injected twice before injections of HV and All in 11 rats. Results: GN was detected only in the $\mathrm{H}+\mathrm{A}$ group; observed first on day 2 and aggravated thereafter. HIF-1 $\alpha$ was expressed in the glomeruli and renal tubules in the $A$ and $\mathrm{H}+\mathrm{A}$ groups. In the $\mathrm{H}+\mathrm{A}$ group, $\mathrm{GN}$ was remark-
\end{abstract}

ably reduced by $\mathrm{CoCl}_{2}$ pretreatment ( 44.9 to $12.2 \%, \mathrm{p}<$ 0.01). Conclusion: Both HV and All were critical for the development of GN, and HIF-1 $\alpha$ remarkably attenuated the progression of $\mathrm{GN}$.

Copyright $@ 2005$ S. Karger AG, Basel

\section{Introduction}

Many animal studies have been performed in attempts to overcome the poor prognosis of chronic renal failure due to diabetic nephropathy and glomerulonephritis (GN) [1-5]. Although factors involved in the pathogenesis of GN have been intensively investigated, the development of a proper animal GN model with high reproducibility and simplicity as well as a model without time-consuming process is required. Experimental rat models of GN are classified into several groups in terms of the pathophysiological mechanisms of renal diseases. Antiglomerular basement membrane nephritis was developed with depositions of immune complex using anti-glomerular basement membrane antibody [3, 6], tubulointerstitial injury was caused by cyclosporine A [4] and injury of renal tubules by ischemia [5]. However, there are few rat GN models with mainly pathological features in the glo-

\begin{tabular}{ll}
\hline KARGER & ( ) 2005 S. Karger AG, Basel \\
1660-2129/05/1002-0095\$22.00/0 \\
$\begin{array}{l}\text { Fax +4161306 12 34 } \\
\begin{array}{l}\text { E-Mail karger@karger.ch } \\
\text { www.karger.com }\end{array}\end{array}$ & $\begin{array}{l}\text { Accessible online at: } \\
\text { www.karger.com/nee }\end{array}$
\end{tabular}

Yoshihiko Kakinuma, MD, PhD

Department of Cardiovascular Control

Kochi Medical School

Nankoku, Kochi 783-8505 (Japan)

Tel. +81 88880 2311, Fax +81 88880 2310, E-Mail kakinuma@med.kochi-u.ac.jp 


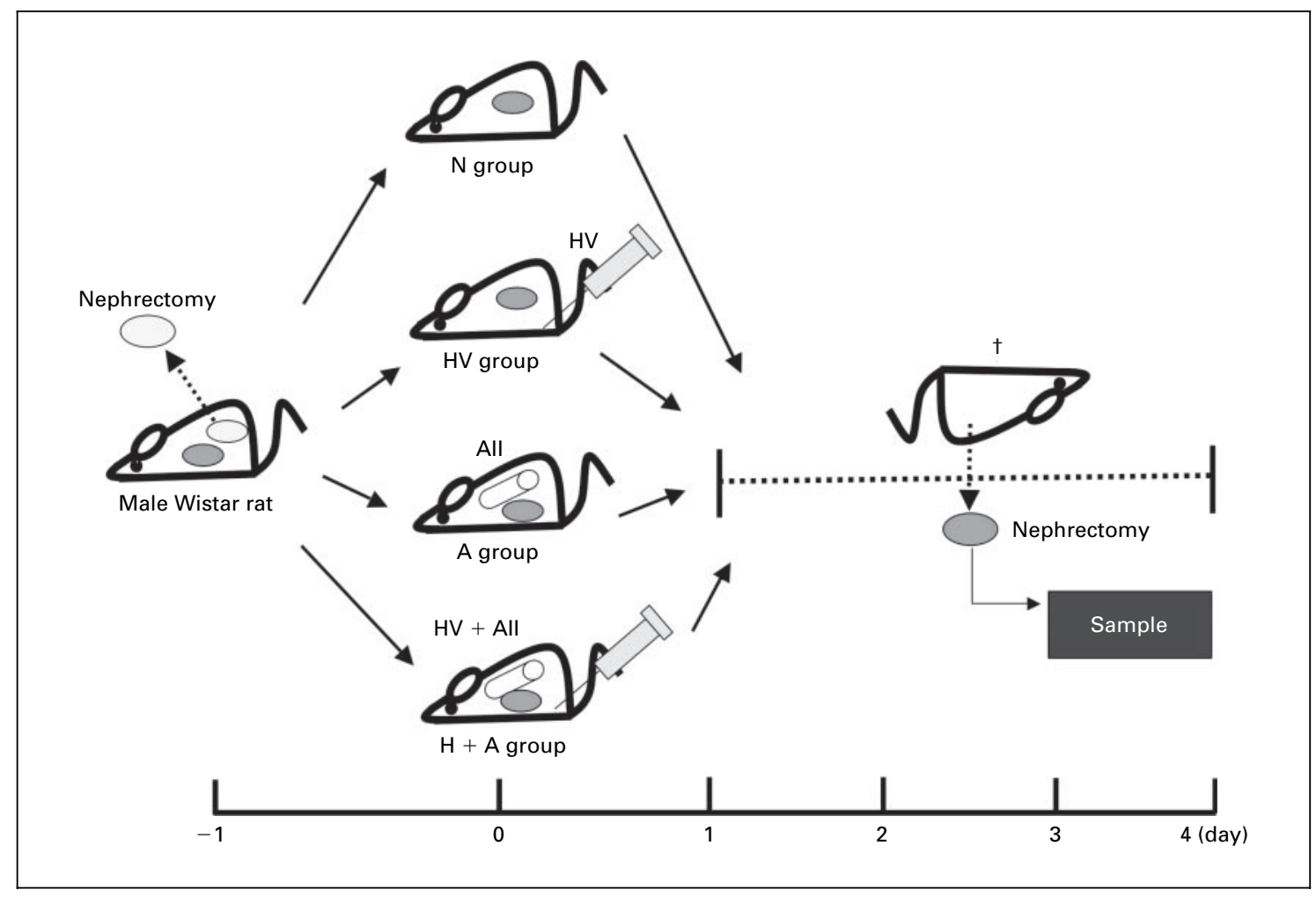

Fig. 1. Study Protocol. All rats are unilaterally nephrectomized on day 1 and divided into 4 groups on day 0 . $N$ group: no injection of reagents. HV group: injection of $3.5 \mathrm{mg} / \mathrm{kg}$ of Habu snake venom (HV). A group: continuous administration of $100 \mathrm{ng} / \mathrm{min}$ of angiotensin II (AII). H+A group: administration of $\mathrm{HV}$ and AII.

meruli that are developed in a short time [7]. Angiotensin II (AII) is known to increase blood pressure through vascular contraction, and to be profoundly involved in cardiovascular hypertrophy and the contraction of intrarenal arteries. AII is also directly involved in the progression of glomerulosclerosis via the effect of hyperfiltration with or without hypertension $[8,9]$. Many studies have revealed important factors involved in the pathogenesis of $\mathrm{GN}$ or factors aggravating GN, but evaluating further factors that suppress the occurrence of GN is also crucial. To investigate the features of renal protection, we focused on hypoxia-inducible factor (HIF)-1 $\alpha$. HIF- $1 \alpha$, a transcriptional factor with formation of a heterodimer with HIF$1 \beta[10]$, is post-transcriptionally regulated and its protein level is elevated by hypoxia through inhibition of ubiquitin-mediated degradation. HIF- $1 \alpha$ is known to be a survival factor responsible for inducing lines of genes supporting cell survival such as glucose metabolism (glucose transporters and glycolytic enzymes), vasomotor regulation (heme oxygenase-1 and endothelin-1), angiogenic growth (vascular endothelial growth factor), and anemia control (erythropoietin and transferrin) [11-13]. Recent studies have demonstrated that non-hypoxic stimuli like AII can also activate HIF- $1 \alpha[14,15]$, but the role of HIF$1 \alpha$ induction in attenuating the progression of GN remains to be elucidated. Accordingly, we developed a new rat GN model by coadministration of AII with Habu snake venom (HV) and investigated whether preinduction of HIF-1 $\alpha$ leads to renal protection.

\section{Materials and Methods}

\section{Development of Rat GN Model}

All experiments were approved by the institutional review board for the care of animal subjects and were performed in accordance with guidelines of Kochi Medical School. Nine-week-old male Wistar rats (180-220 g) were purchased from Japan SLC (Shizuoka, Japan). Rats were unilaterally nephrectomized on day 1 . On day 0 , the rats were divided into 4 groups. In the first group, no treatment was performed with any reagents or surgical procedure $(\mathrm{N}$ group, $\mathrm{n}=6)$. In the second group, rats were injected with $3.5 \mathrm{mg} / \mathrm{kg}$ of HV (SigmaAldrich Co., Steinheim, Germany) through the femoral vein (HV group, $\mathrm{n}=11)$. In the third group, rats were continuously adminis- 
tered with AII (100 ng/min; Peptide Institute Inc., Osaka, Japan) using Alzet osmotic pumps (DURECT Co., Cupertino, Calif., USA) (A group, $\mathrm{n}=11$ ). In the fourth group, rats were administered with both $\mathrm{HV}$ and $\mathrm{AII}(\mathrm{H}+\mathrm{A}$ group, $\mathrm{n}=22)$. Rats were sacrificed on day 1 , 2, 3 or 4, and kidneys excised for histochemical analysis (fig. 1).

\section{Measurement of Systolic Blood Pressure}

Systolic blood pressure (SBP) was measured by the tail-cuff method with an electro-sphygmomanometer (BP-98A; Softron Co., Tokyo, Japan). SBP was measured in conscious rats every day from day 1 to 2 . The SBP value for each rat was calculated as the average of 3 separate measurements at each session. SBP measurement was performed between 9 and 12 a.m. by a single blinded investigator.

\section{Measurements of Serum Urea Nitrogen and Creatinine}

Before the sacrifice, blood samples were obtained via an axillary vein for determination of serum urea nitrogen (UN) and creatinine (Cr) levels. Serum UN and Cr levels were determined enzymatically with automation-analysis equipment (Hitachi 7350; Hitachi Co., Ibaragi, Japan) in our laboratory center.

\section{Histological Analysis}

To evaluate the progression of GN in our animal model, histological analyses were performed using the periodic acid-Schiff (PAS) and periodic acid-methenamine silver (PAM) reagents. After the specimens were paraffin embedded, $4-\mu \mathrm{m}$-sectioned samples were stained with PAS and PAM reagents and counterstained with hematoxylin. For quantitative analysis, the ratio of damaged glomeruli to all glomeruli in the sectioned sample was calculated and the percentage of GN in the section was evaluated. Moreover, semiquantitative analysis was performed to evaluate more precisely the morphological changes of our GN model according to the protocol in previous studies $[16,17]$. A minimum of 20 glomeruli (ranging from 20 to 60 glomeruli) in each specimen were examined and the severity of the mesangiolysis lesion was graded from 0 to $4+$ according to the percentage of glomerular involvement; a $1+$ lesion represented an involvement of $25 \%$ of the glomerulus while a $4+$ lesion indicated that $100 \%$ of the glomerulus was involved. Thus, the mesangiolysis score (MES) was then obtained by multiplying the degree of damage ( 0 to $4+$ ) by the percentage of the glomeruli with the lesion. Tubular injuries including tubular necrosis or occlusion of collecting ducts by cast material were graded as mild $(1+)$, moderate $(2+)$, or severe $(3+)$

\section{Western Blot Analysis}

Nuclear protein from whole kidney was prepared using NE-PER Nuclear and Cytoplasmic Extraction Reagents (Pierce Biotechnology Inc., Rockford, Ill., USA). Nuclear protein was electrophoresed using $10 \%$ SDS-PAGE gels and transferred to polyvinylidene difluoride membrane (Immobilon-P; Millipore Corp., Bedford, Mass., USA). A monoclonal IgG HIF-1 $\alpha$ antibody $\alpha 67$ (Novus Biological, Littleton, Colo., USA) was used; a horseradish peroxidase-conjugated antibody (Promega Co., Madison, Wisc., USA) was used as a secondary antibody. The ECL Western blotting systems (Amersham Bioscience, Uppsala, Sweden) was used for detection.

Immunohistochemical Analysis

Paraffin sections including the samples were dewaxed in xylene and rehydrated in a series of ethanol, and then washed in distilled water before staining procedures. According to the instruction pro- vided by the manufacturer, HIF-1 $\alpha$ was identified with rabbit polyclonal anti-HIF-1 $\alpha$ antibody H-206 (Santa Cruz Biotechnology, Calif., USA) utilizing the catalyzed signal amplification system (Dako, Hamburg, Germany) based on the streptavidin-biotin-peroxidase reaction. Antigen retrieval was performed for $5 \mathrm{~min}$ in a preheated Dako target retrieval solution using a microwave. Incubation procedures were performed in a humidified chamber. Following the incubation, specimens were washed 3 times in TBST buffer. The specificity of staining was confirmed by substitution of the primary antibody for a normal rabbit IgG and additionally by an immunohistochemical reaction without a primary antibody but with the secondary antibody alone.

\section{An Experiment Using Cobalt Chloride as a Pretreatment}

Rats were twice subcutaneously administered $30 \mathrm{mg} / \mathrm{kg}$ of cobalt chloride $\left(\mathrm{CoCl}_{2}\right)$ at a 12-hour interval $\left(\mathrm{CoCl}_{2}\right.$ group $)(\mathrm{n}=11)$, followed by unilateral nephrectomy. Then, the rats were administered with $\mathrm{HV}$ and AII. As a comparison, rats were injected with $0.9 \%$ $\mathrm{NaCl}$ solution instead of $\mathrm{CoCl}_{2}$, followed by the same protocol as the $\mathrm{CoCl}_{2}$ group $(\mathrm{n}=11)$. After $\mathrm{CoCl}_{2}$ administration, however, before injection of $\mathrm{HV}$ and $\mathrm{AII}$, a kidney was excised as a sample to examine expression level of HIF- $1 \alpha\left(\mathrm{CoCl}_{2}\right.$ Pre). Likewise, 2 days after administration of $\mathrm{HV}$ and $\mathrm{AII}$, a kidney was also excised $\left(\mathrm{CoCl}_{2}\right.$ Day 2). To compare the expression level of HIF- $1 \alpha$ by $\mathrm{CoCl}_{2}$ before $\mathrm{GN}$ and the severity of pathology of GN, we investigated whether preinduction of HIF- $1 \alpha$ is involved in renal protection.

\section{Statistical Analysis}

Data are reported as mean \pm SEM. A paired $t$ test was used for paired samples and Student's $t$ test was used to compare the 2 groups. One-way layout analysis of variance or repeated measures of analysis of variance were used to compare multiple groups. If the $p$ value was significant, Scheffé's multiple comparison was performed. A $p$ value $<0.05$ was considered significant.

\section{Results}

\section{AII Combined with HV Developed GN}

Morphological studies using PAS and PAM staining revealed that there are no glomerular or tubular injuries in $\mathrm{N}$ group (fig. 2a), HV group (fig. 2b), A group (fig. 2c), however, GN was detected only in the $\mathrm{H}+\mathrm{A}$ group (fig. 2e). Although renal tubular casts were observed, glomerular changes were scarcely observed on day 1 after AII and HV administration (fig. 2d, 3). GN was initially detected on day 2 (fig. 2e, f, 3), followed by further aggravation during the time course (data not shown). Renal tubular injury including tubular necrosis was not remarkable, and extensive cellular infiltration was not found in the interstitial regions (fig. 3). On the other hand, characteristic focal and segmental mesangiolysis, explained as capillary aneurysmal ballooning, was observed with dilatation of glomerulus (fig. 2e, f). The rate of occurrence of GN on day 2 was $44.9 \pm 2.6 \%$, and the MES score of the $\mathrm{H}+\mathrm{A}$ 

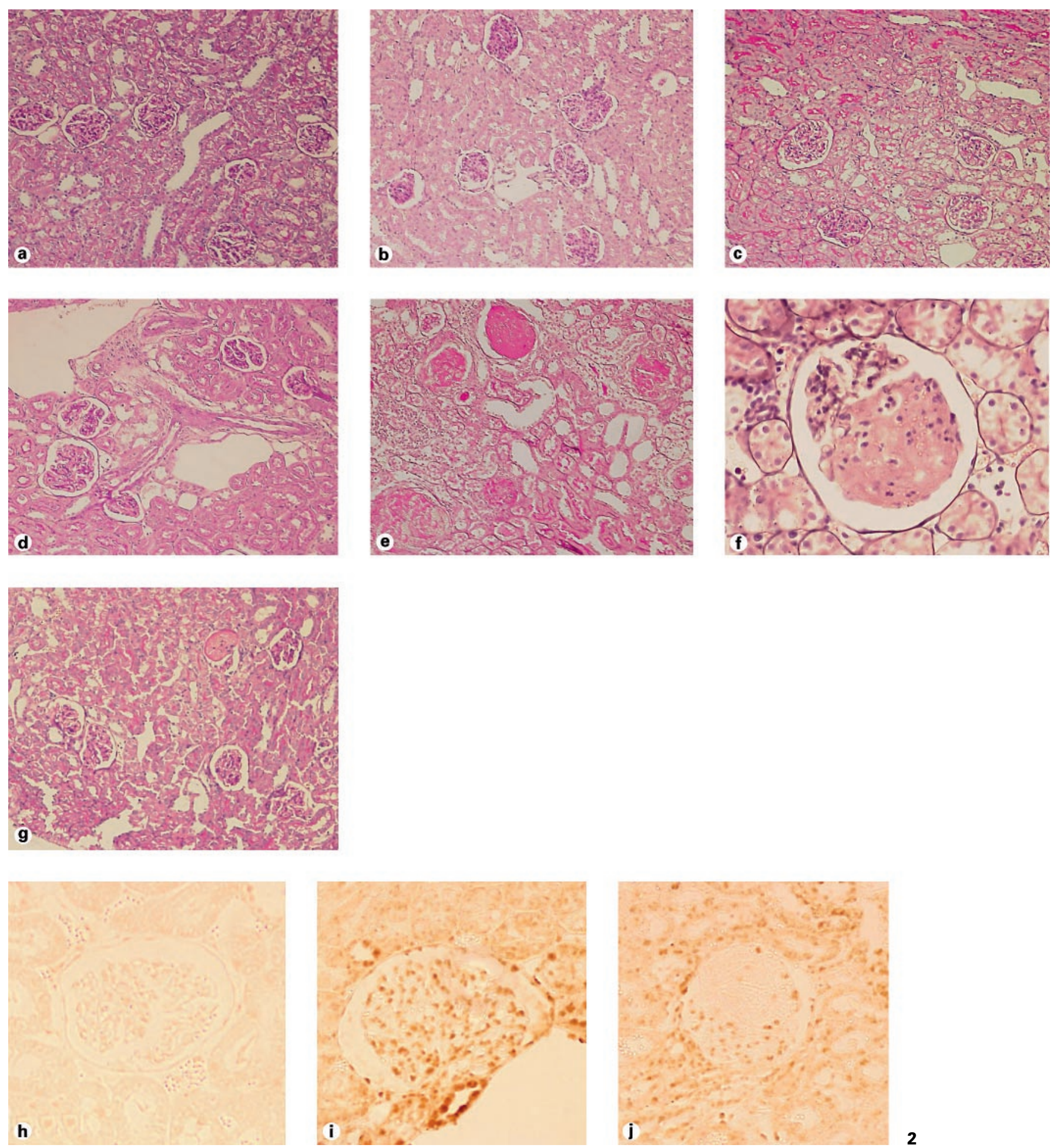

2 
group was $199 \pm 15$ (fig. 3). On the other hand, in the HV group, less than $2 \%$ had morphologic changes of mesangiolysis during 4 days, and the MES score was $10 \pm 5$ (fig. 2b, 3). Moreover, in the A group, there were no morphologic changes during the time course (fig. 2c).

\section{Changes in Serum $\mathrm{UN}$ and $\mathrm{Cr}$}

Serum UN and $\mathrm{Cr}$ were $18.4 \pm 0.7$ and $0.31 \pm$ $0.01 \mathrm{mg} / \mathrm{dl}$, respectively, on day 2 in the $\mathrm{N}$ group. In the $\mathrm{H}+\mathrm{A}$ group, serum $\mathrm{UN}$ and $\mathrm{Cr}$ levels increased to $41.5 \pm$ 4.0 and $0.57 \pm 0.05 \mathrm{mg} / \mathrm{dl}$, respectively, on day 2 ; significantly higher than those in the $\mathrm{N}$ group (fig. $4 \mathrm{a}, \mathrm{b}$ ). In contrast, serum UN and $\mathrm{Cr}$ levels in the $\mathrm{H}+\mathrm{A}$ group on day 1 $(24.0 \pm 1.8$ and $0.42 \pm 0.02 \mathrm{mg} / \mathrm{dl}$, respectively) were similar to the level of the $\mathrm{N}$ group. There were no significant differences in serum $\mathrm{UN}$ and $\mathrm{Cr}$ level among the $\mathrm{HV}$, A and $\mathrm{N}$ groups.

\section{SBP Response}

SBP values of each group are shown in figure 4c. There were no significant differences in SBP after nephrectomy among the 4 groups. Administration of AII caused a significant increase of SBP on day 1 (186 \pm $4 \mathrm{~mm} \mathrm{Hg}$ ) and persisted to day $2(192 \pm 1 \mathrm{~mm} \mathrm{Hg})$. SBP in the $\mathrm{H}+\mathrm{A}$ group on day $2(183 \pm 3 \mathrm{~mm} \mathrm{Hg})$ was comparable to that in the A group. Administration of $\mathrm{HV}$ had no influence on SBP during the 2 days.

\section{Expression Level of HIF-1 $\alpha$ Protein}

Western blot analysis revealed that the expression level of $\mathrm{HIF}-1 \alpha$ protein increased in the $\mathrm{H}+\mathrm{A}$ and A groups (fig. 5a), compatible with the results of immunohistochemical analysis. Expressions of HIF-1 $\alpha$ protein were observed in the $\mathrm{A}$ and $\mathrm{H}+\mathrm{A}$ groups, but protein expres-

Fig. 2. Glomerulonephritis is developed with the combination of HV and AII, and HIF- $1 \alpha$ is induced in the intact glomeruli. There are no glomerular or tubular injuries in $\mathrm{N}$ group (a), HV group (b), A group (c) and $\mathrm{H}+\mathrm{A}$ group on day 1 (d). Damaged glomeruli, characterized by extensive mesangiolysis, are observed in H+A group on day 2 . PAS staining. Magnification, $\times 100(\mathbf{e})$. Focal and segmental mesangiolysis with large capillary aneurysmal ballooning are observed in the $\mathrm{H}+\mathrm{A}$ group on day 2. PAM staining. Magnification, $\times 400(\mathbf{f})$. The number of GN was significantly less in pretreatment with $\mathrm{CoCl}_{2}$ than without. PAS staining. Magnification, $\times 100(\mathbf{g})$. Immunoreactive HIF- $\alpha$-positive signals are not detected in the $\mathrm{N}$ group (h). Nuclear HIF-1 $\alpha$ signals are observed in a glomerulus and tubules in the A group. Magnification, $\times 200$ (i). A glomerulus in the $\mathrm{H}+\mathrm{A}$ group on day 2 possesses intact cells with HIF-1 $\alpha$-positive signals; in contrast, other parts have few HIF-1 $\alpha$ signals due to mesangiolysis. Magnification, $\times 200(\mathbf{j})$.

HIF-1 $\alpha$ in Glomerulonephritis

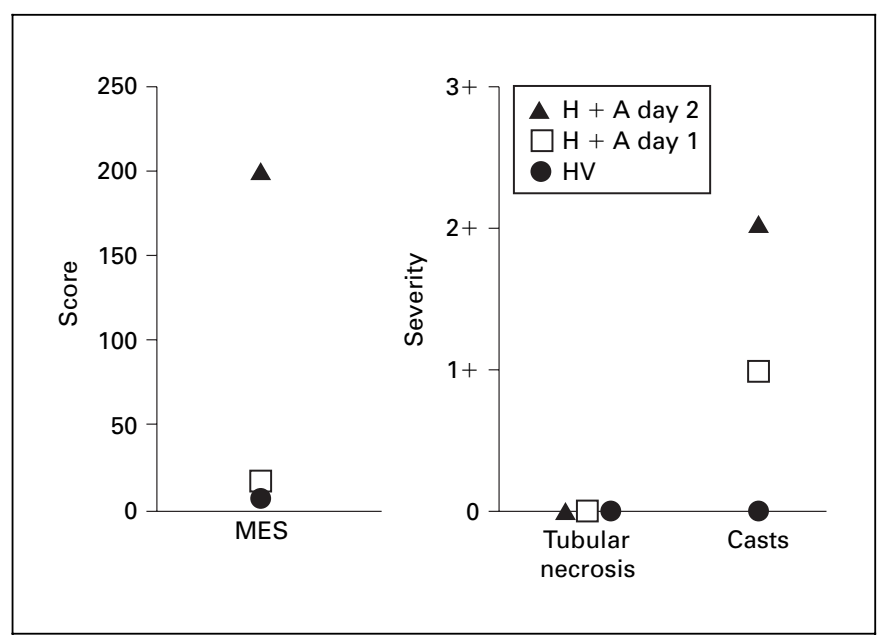

Fig. 3. Semiquantitative analysis of morphologic changes in our glomerulonephritis model. The main lesion in the $\mathrm{H}+\mathrm{A}$ group is initially detected on day 2 as mesangiolysis in glomeruli; however, there are no tubular lesions of necrosis except for tubular casts; in contrast, there are no morphological changes in the $\mathrm{N}$ and $\mathrm{A}$ groups. $\mathrm{MES}=$ Mesangiolysis score.

sion was not detected in the $\mathrm{N}$ and $\mathrm{HV}$ groups. These data suggest that HIF- $1 \alpha$ was induced mainly by AII, and, at least in part, was related to the pathogenesis of GN or to the defense mechanism against the progression of GN.

\section{Induction of HIF-1 $\alpha$ in Glomeruli and Renal Tubules}

Immunohistochemical study demonstrated positive nuclear staining of HIF-1 $\alpha$ in glomeruli, renal tubules (fig. 2i, j), collecting ducts and epithelium of the papilla (data not shown) in the $\mathrm{A}$ and $\mathrm{H}+\mathrm{A}$ groups. In contrast, no positive nuclear signals were detected in the $\mathrm{N}$ (fig. $2 \mathrm{~h}$ ) and HV (data not shown) groups. HIF-1 $\alpha$-positive cells were mainly detected in mesangial cells in glomeruli (fig. 2i, j). As demonstrated, especially in the $\mathrm{H}+\mathrm{A}$ group (fig. 2j), HIF-1 $\alpha$ was expressed in the intact part of the glomerulus, but not in the injured part of the same glomerulus. Furthermore, nuclear HIF-1 $\alpha$-positive signals were observed in smooth muscle cells in peripheral renal arteries (data not shown).

\section{$\mathrm{CoCl}_{2}$ Pretreatment Inhibits the Progression of $\mathrm{GN}$}

To further investigate whether HIF-1 $\alpha$ is involved in the development of nephropathy or in the antiprogressive action, we pretreated rats with $\mathrm{CoCl}_{2}$. As demonstrated in figure $5 \mathrm{~b}$, pretreatment with $\mathrm{CoCl}_{2}$ increased HIF- $1 \alpha$ expression before administration of HV and AII (Pre-1), 


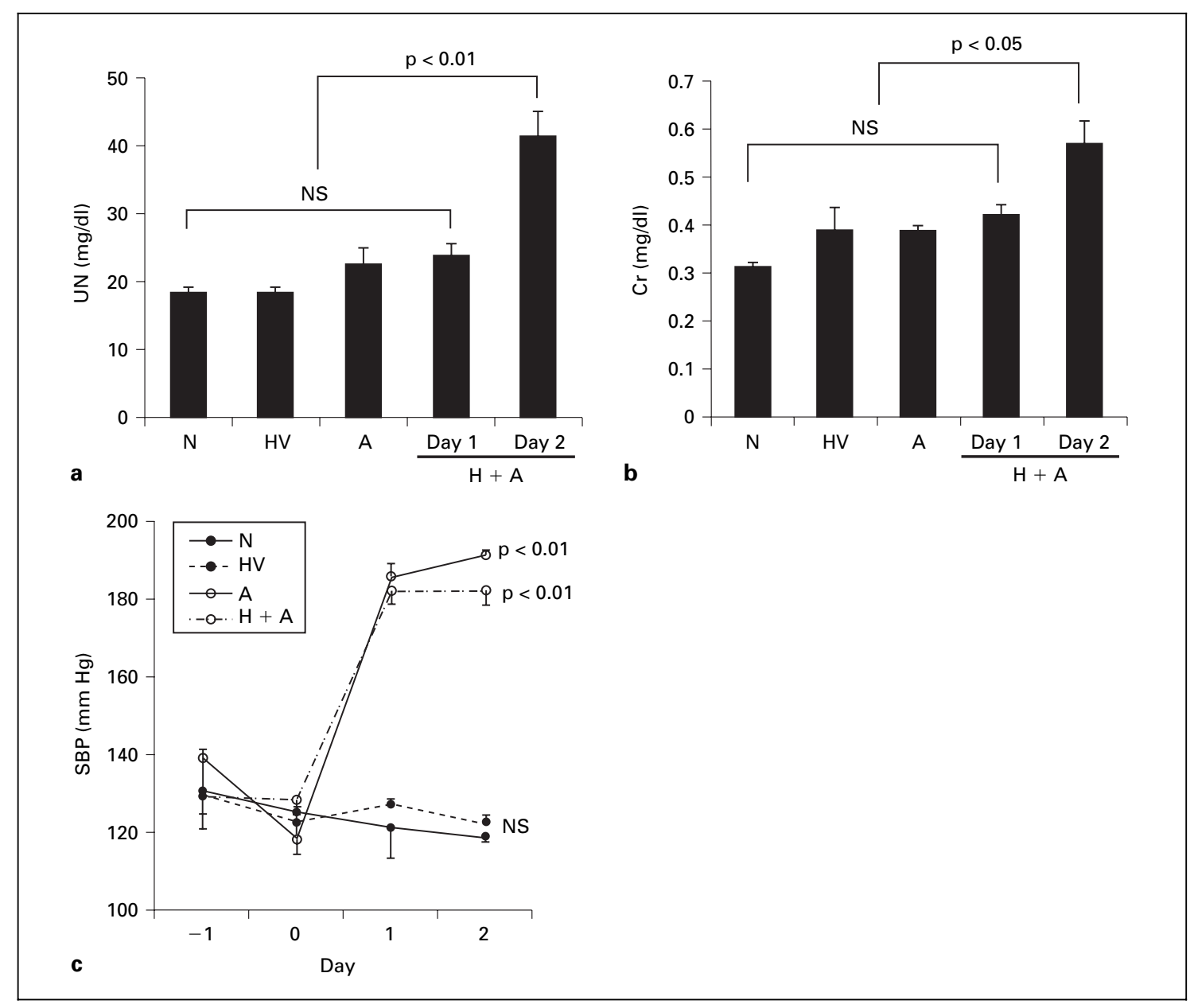

Fig. 4. Serum UN, $\mathrm{Cr}$ and SBP are increased with the combination of $\mathrm{HV}$ and AII. The serum UN (a) and $\mathrm{Cr}(\mathbf{b})$ levels in the $\mathrm{H}+\mathrm{A}$ group on day 2 are significantly higher than other groups. SBP increases significantly with administration of AII (A and $\mathrm{H}+\mathrm{A}$ groups) (c).

suggesting that HIF-1 $\alpha$ was induced by $\mathrm{CoCl}_{2}$ before development of GN. Even on day 2, the expression level of HIF-1 $\alpha$ was increased in the $\mathrm{CoCl}_{2}$ group $\left(\mathrm{CoCl}_{2}\right.$ Day $2-1)$. In the $\mathrm{CoCl}_{2}$ group, focal mesangiolysis with glomeruli enlargement was still observed, but the number of GN was much less than in those without $\mathrm{CoCl}_{2}$ pretreatment (fig. 2g).

Thus, 7 of 11 rats $(63.6 \%)$ with $\mathrm{CoCl}_{2}$ pretreatment were rescued from GN alone, while the other 4 (36.4\%) were not; showing a comparable severity level of GN with the non- $\mathrm{CoCl}_{2}$ group. As demonstrated in figure 5b, unlike Pre-1, Pre-2 did not induce HIF-1 $\alpha$ with $\mathrm{CoCl}_{2}$ and showed no $\mathrm{CoCl}_{2}$ suppression of GN. The ratio between rats rescued or not rescued from GN was comparable with that between preinduction and noninduction of HIF-1 $\alpha$ by $\mathrm{CoCl}_{2}$, as demonstrated in figure $5 \mathrm{c}$. In the $\mathrm{CoCl}_{2}$ group, the rate of GN from each rat decreased to $12.2 \pm$ $2.1 \%$, which was in great contrast to $44.9 \pm 2.6 \%$ in the non- $\mathrm{CoCl}_{2}$ group. Furthermore, serum $\mathrm{UN}$ and $\mathrm{Cr}$ levels on day 2 were significantly lower in the $\mathrm{CoCl}_{2}$ than in the non- $\mathrm{CoCl}_{2}$ group $(\mathrm{p}<0.05)$ (fig. $\left.6 \mathrm{a}, \mathrm{b}\right)$, despite comparable SBP values between the 2 groups (fig. $6 \mathrm{c}$ ).

\section{Discussion}

In this study, we developed a new model of GN induced by both HV and AII. This model has several distinct characteristics. First, GN developed rapidly, and was detected on the second day after administration of 

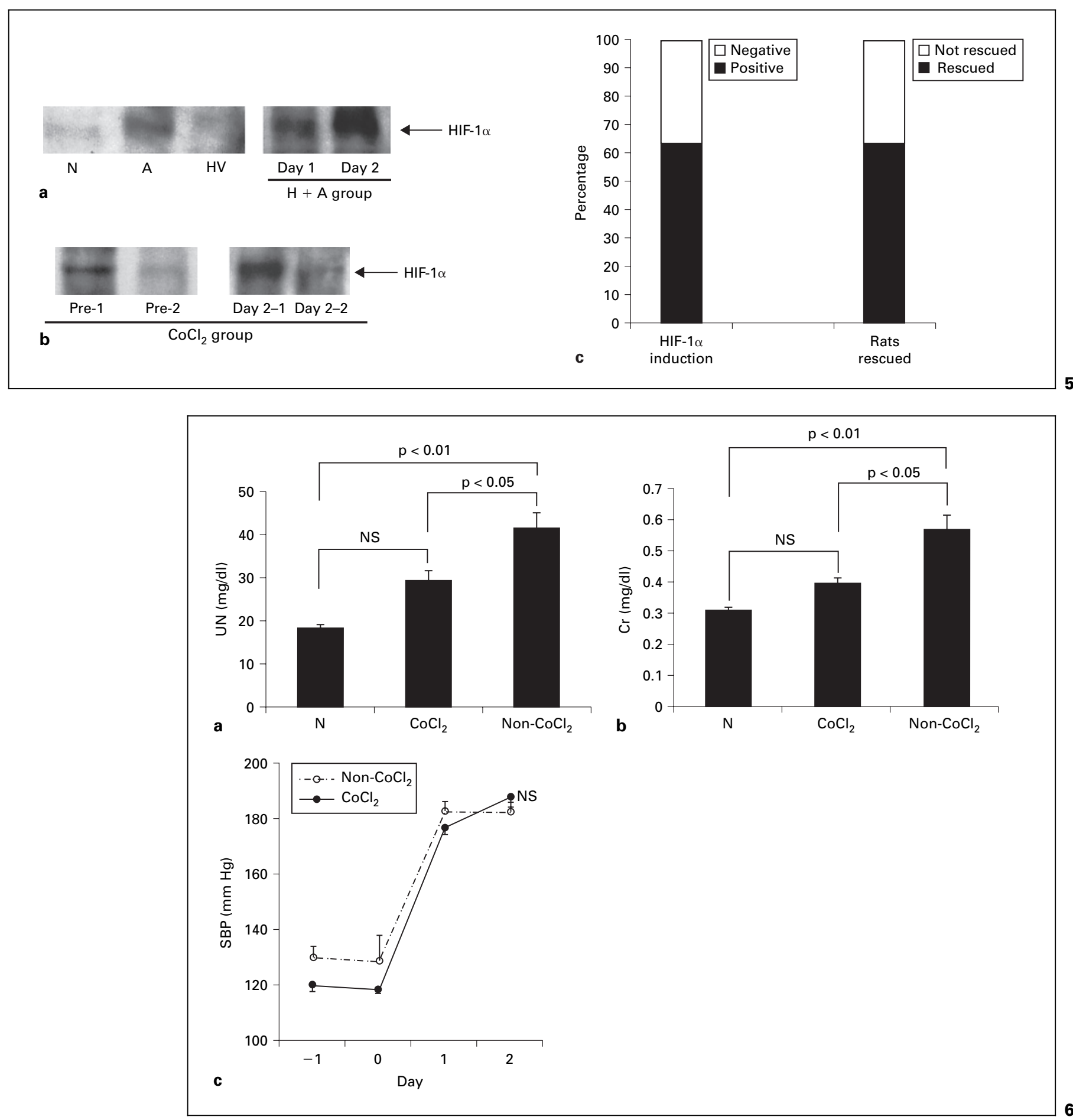

Fig. 5. The protein level of HIF-1 $\alpha$ is increased by administration of $\mathrm{HV}$ and AII, and pretreatment of $\mathrm{CoCl}_{2}$ increases HIF- $1 \alpha$ expression before development of GN. HIF-1 $\alpha$ is not detected in the N and HV groups (Day 2). However, HIF-1 $\alpha$ is detected in A (Day 2) and $\mathrm{H}+\mathrm{A}$ (Days 1 and 2) groups (a). The $\mathrm{CoCl}_{2}$ group, in accord with the level of HIF- $1 \alpha$ induction, was divided into 2 groups. HIF- $1 \alpha$ is greatly induced before the development of $\mathrm{GN}\left(\mathrm{CoCl}_{2}\right.$ group Pre-1), and is followed by a high level $\left(\mathrm{CoCl}_{2}\right.$ group Day $\left.2-1\right)$; in contrast, it is not efficiently induced $\left(\mathrm{CoCl}_{2}\right.$ group Pre-2), and also is scarcely detected on day $2\left(\mathrm{CoCl}_{2}\right.$ group Day 2-2) (b). The rate of preinduction of HIF$1 \alpha$ by $\mathrm{CoCl}_{2}$ is comparable with that of the inhibition of $\mathrm{GN}$ by $\mathrm{CoCl}_{2}$ (c).

Fig. 6. Pretreatment with $\mathrm{CoCl}_{2}$ attenuates GN. Serum UN (a) and $\mathrm{Cr}$ (b) levels in the $\mathrm{CoCl}_{2}$ group on day 2 are significantly decreased compared to those in the non- $\mathrm{CoCl}_{2}$ group. There is no significant difference in SBP between the $\mathrm{CoCl}_{2}$ and non- $\mathrm{CoCl}_{2}$ groups (c). 
$\mathrm{HV}$ and AII. Many models of GN have been reported including 5/6 nephrectomized and Thy-1.1 nephritis models $[18,19]$. However, these models take a long time to develop nephropathy. In contrast, our protocol induced GN in 2 days, suggesting that one of the advantages our model has over others is in terms of the time course. Further, pathological findings were restricted to glomerular regions without remarkable tubular or interstitial lesions. Since our GN model developed within 2 days, it also has advantages for disclosing the specifically critical time point of the development of GN. Furthermore, the development rate of GN was almost $100 \%$, indicating the high reproducibility of our model. This basis of the rat model was initially developed by Barnes et al. [20] who reported that the progression of AII-induced renal injury was accelerated by pre-existing injury induced by HV; our model, which now optimizes the reproducibility of GN, is a modification of theirs.

Habu-induced nephropathy was reported to develop within 1 day by a dose of $2.0-4.0 \mathrm{mg} / \mathrm{kg} \mathrm{HV}$ (in our model $3.5 \mathrm{mg} / \mathrm{kg}$ ) and the main pathological change was 'mesangiolysis' [21, 22]. However, for reasons we have not as yet ascertained, in our study no rats showed Habu-nephropathy-specific pathological findings during the first week in the HV group. On the other hand, AII is one of the major factors responsible for the pathogenesis of $\mathrm{GN}$, because it remarkably increases glomerular pressure causing hyperfiltration, production of extracellular matrix and expression of lines of genes involving GN [23-25]. Further, since AII has some ischemic effects on the kidneys, there is the possibility that an AII-induced ischemic effect causes the GN depicted in our model. However, as demonstrated in this study, glomerular injury was predominantly observed, and was not associated with renal tubular lesions, i.e. tubular necrosis suggesting renal ischemia. Therefore, in accordance with the pathological characteristic of this GN, AII-induced renal ischemia may not be responsible for its development in our model. Additionally, in this study, SBP increased in the A and $\mathrm{H}+\mathrm{A}$ groups, but GN was not induced in the A group. Therefore, GN in our model was induced not by HV or AII alone, but by the combination of $\mathrm{HV}$ and $\mathrm{AII}$, independent of any increase in systemic blood pressure.

$\mathrm{HIF}-1 \alpha$ is a master transcriptional factor, transactivating the expression of many genes important for cell survival under hypoxic conditions [11-13, 26]. These genes are responsible for glycolysis, angiogenesis, proliferation and iron metabolism, all of which are induced by hypoxic stress; thus, the induction of HIF-1 $\alpha$ is a marker of hypoxia. HIF-1 $\alpha$ is regulated at the post-translational level by the proteasome system through ubiquitination with von Hippel-Lindau (VHL) protein [27, 28]. As previously reported, this regulation of HIF-1 $\alpha$ protein level is dependent on the concentration of oxygen. Hypoxia induces enhancement of HIF-1 $\alpha$ protein stability leading to the elevation of the protein level due to inhibition of degradation by VHL. Therefore, hypoxia induces adaptation in cells including induction of HIF-1 $\alpha$; the hypoxic pathway. On the other hand, a line of evidence recently accumulated suggests that HIF-1 $\alpha$ is also regulated independently of oxygen concentration through the nonhypoxic pathway $[14,15]$. AII is reported to regulate HIF-1 $\alpha$ both at transcriptional and post-translational levels in vascular smooth muscle cells cultured under normoxic condition through the AII type 1 receptor $[14,15]$. Moreover, HIF$1 \alpha$ is also post-translationally regulated in several cell lines in the presence of tumor necrosis factor- $\alpha$ or nitric oxide independent of oxygen contents [29, 30].

As demonstrated in this study, immunoreactivity of HIF-1 $\alpha$ was not detected in the $\mathrm{N}$ group (no treatment group), but HIF-1 $\alpha$ was detected in the nuclei of glomerular, tubular and epithelial cells of the papilla by administration of AII alone or AII and HV together. This is the first evidence showing that HIF-1 $\alpha$ was detected in the kidney by AII, independent of systemic hypoxic stress. As indicated here, HIF-1 $\alpha$ was found to be expressed only in intact, not damaged glomeruli. Even within a glomerulus, only the intact part of glomerular cells expressed HIF-1 $\alpha$. Considering the fact that induction of HIF-1 $\alpha$ is one of the defense mechanisms for cell survival [31-33], our data indicate that induction of HIF-1 $\alpha$ is a marker of glomeruli survival; indeed, it could be a marker of renal protection.

To further investigate whether HIF-1 $\alpha$ is involved in the progression or protection of GN, preinduction of HIF$1 \alpha$ was performed with $\mathrm{CoCl}_{2}$ before administration of $\mathrm{HV}$ and AII. Surprisingly, the induction of HIF-1 $\alpha$ by $\mathrm{CoCl}_{2}$ pretreatment attenuated the progression of $\mathrm{GN}$; the level of GN was reduced from 44.9 to $12.2 \%$ and the incidence of GN was reduced from 100 to $36.4 \%$. Furthermore, as indicated, the preinduction of HIF-1 $\alpha$ actually affects the inhibition of GN, because the rate of HIF-1 $\alpha$ induction was parallel with that of the attenuation of GN. Therefore, our data suggest that HIF-1 $\alpha$ is involved, at least in part, in the defense mechanism against the progression of GN, and hence could be a marker for renal protection.

AII is reported to induce HIF-1 $\alpha[14,15]$ and plays a partial role in the renal protective effect; however, the other effects of AII, such as increasing glomerular pressure and modulating gene expression involving in the renal e102

Nephron Exp Nephrol 2005;100:e95-e103
Kudo/Kakinuma/Mori/Morimoto/ Karashima/Furihata/Sato/Shuin/Sugiura 
failure, may overcome any protective effect of AIIinduced HIF-1 $\alpha$, and so as a result it may lead to the progression of GN.

In conclusion, we developed a highly reproducible GN model by combining HV and AII. Preinduction of HIF-1 $\alpha$ remarkably attenuated the progression of $\mathrm{GN}$, indicating that HIF-1 $\alpha$ was involved in the defense mechanism of the kidney.

\section{Acknowledgments}

This work was supported by Grants-in-Aid for Scientific Research from the Ministry of Education, Science and Culture (No. 14657409). We thank Dr. Masami Nakatani, Dr. Noriko Kishimoto, Dr. Ichiro Yamasaki, Dr. Yoshitaka Kumon, Dr. Hiroaki Takeuchi, Dr. Jun Imamura, Dr. Mikio Kamioka, Ms. Chiaki Kawada, Ms. Chizuko Sugimoto, and Mr. Takuya Yamaguchi for their helpful advice and generous support.

\section{References}

$>1$ Rifai A, Small PA Jr, Teague PO, Ayoub EM: Experimental IgA nephropathy. J Exp Med 1979;150:1161-1173.

-2 Ishizaki M, Masuda Y, Fukuda Y, Yamanaka N, Masugi Y, Shichinohe K, Nakama K: Renal lesions in a strain of spontaneously diabetic WBN/Kob rats. Acta Diabetol Lat 1987;24:2735.

3 Banks KL: Glomerulonephritis, autoimmunity, autoantibody. Animal model: Anti-glomerular basement membrane antibody in horses. Am J Pathol 1979;94:443-446.

$\checkmark 4$ Elzinga LW, Rosen S, Bennett WM: Dissociation of glomerular filtration rate from tubulointerstitial fibrosis in experimental chronic cyclosporine nephropathy: Role of sodium intake. J Am Soc Nephrol 1993;4:214-221.

$\checkmark 5$ Arendshorst WJ, Finn WF, Gottschalk CW: Pathogenesis of acute renal failure following temporary renal ischemia in the rat. Circ Res 1975;37:558-568.

6 Wilson CB, Dixon FJ: Immunopathologic mechanisms of renal disease. Ric Clin Lab 1975;5:17-38.

7 Masuda Y, Shimizu A, Mori T, Ishiwata T, Kitamura H, Ohashi R, Ishizaki M, Asano G, Sugisaki Y, Yamanaka N: Vascular endothelial growth factor enhances glomerular capillary repair and accelerates resolution of experimentally induced glomerulonephritis. Am J Pathol 2001;159:599-608.

$>8$ Kim S, Iwao H: Molecular and cellular mechanisms of angiotensin II-mediated cardiovascular and renal diseases. Pharmacol Rev 2000;52: 11-34.

$>9$ Lee LK, Meyer TW, Pollock AS, Lovett DH: Endothelial cell injury initiates glomerular sclerosis in the rat remnant kidney. J Clin Invest 1995;96:953-964

$\checkmark 10$ Huang LE, Arany Z, Livingston DM, Bunn HF: Activation of hypoxia-inducible transcription factor depends primarily upon redox-sensitive stabilization of its alpha subunit. J Biol Chem 1996;271:32253-32259.

-11 Wang, GL, Jiang BH, Rue EA, Semenza GL: Hypoxia-inducible factor 1 is a basic-helixloop-helix-PAS heterodimer regulated by cellular $\mathrm{O}_{2}$ tension. Proc Natl Acad Sci USA 1995; 92:5510-5514.
2 Rosenberger C, Mandriota S, Jurgensen JS, Wiesener MS, Horstrup JH, Frei U, Ratcliffe PJ, Maxwell PH, Bachmann S, Eckardt KU: Expression of hypoxia-inducible factor-1alpha and -2alpha in hypoxic and ischemic rat kidneys. J Am Soc Nephrol 2002;13:1721-1732.

13 Wenger RH, Rolfs A, Marti HH, Guenet JL, Gassmann M: Nucleotide sequence, chromosomal assignment and mRNA expression of mouse hypoxia-inducible factor-1 alpha. Biochem Biophys Res Commun 1996;223:54-59.

14 Richard DE, Berra E, Pouyssegur J: Nonhypoxic pathway mediates the induction of hypoxia-inducible factor 1alpha in vascular smooth muscle cells. J Biol Chem 2000;275:2676526771

15 Page EL, Robitaille GA, Pouyssegur J, Richard DE: Induction of hypoxia-inducible factor-1alpha by transcriptional and translational mechanisms. J Biol Chem 2002;277:48403-48409.

16 Raij L, Azar S, Keane W: Mesangial immune injury, hypertension, and progressive glomerular damage in Dahl rats. Kidney Int 1984;26: 137-143.

17 Linas SL, Shanley PF, Whittenburg D, Berger E, Repine JE: Neutrophils accentuate ischemia-reperfusion injury in isolated perfused rat kidneys. Am J Physiol 1988;255:F728-F735.

18 Romero F, Rodriguez-Iturbe B, Parra G, Gonzalez L, Herrera-Acosta J, Tapia E: Mycophenolate mofetil prevents the progressive renal failure induced by $5 / 6$ renal ablation in rats. Kidney Int 1999;55:945-955.

19 Kaneko Y, Shiozawa S, Hora K, Nakazawa K: Glomerulosclerosis develops in Thy-1 nephritis under persistent accumulation of macrophages. Pathol Int 2003;53:507-517.

20 Barnes JL, Lisa MS: Origin of interstitial fibroblasts in an accelerated model of angiotensin II (AII)-induced interstitial fibrosis. J Am Soc Nephrol 2001;12:699A3645.

21 Cattell V, Bradfield JW: Focal mesangial proliferative glomerulonephritis in the rat caused by habu snake venom. A morphologic study. Am J Pathol 1977;87:511-524.

22 Kitamura H, Sugisaki Y, Yamanaka N: Endothelial regeneration during the repair process following Habu-snake venom induced glomerular injury. Virchows Arch 1995;427:195-204.

$>23$ Ruggenenti P: Angiotensin-converting enzyme inhibition and angiotensin II antagonism in nondiabetic chronic nephropathies. Semin Nephrol 2004;24:158-167.
24 Tolins JP, Raij L: Effects of amino acid infusion on renal hemodynamics. Role of endothelium-derived relaxing factor. Hypertension 1991;17:1045-1051.

25 Nakamura T, Obata J, Kimura H, Ohno S, Yoshida Y, Kawachi H, Shimizu F: Blocking angiotensin II ameliorates proteinuria and glomerular lesions in progressive mesangioproliferative glomerulonephritis. Kidney Int 1999; 55:877-889.

26 Makino Y, Cao R, Svensson K, Bertilsson G, Asman M, Tanaka H, Cao Y, Berkenstam A, Poellinger L: Inhibitory PAS domain protein is a negative regulator of hypoxia-inducible gene expression. Nature 2001;414:550-554.

27 Neckers LM: aHIF: The missing link between HIF-1 and VHL? J Natl Cancer Inst 1999;91: 106-107.

28 Maxwell PH, Wiesener MS, Chang GW, Clifford SC, Vaux EC, Cockman ME, Wykoff CC, Pugh CW, Maher ER, Ratcliffe PJ: The tumour suppressor protein VHL targets hypoxia-inducible factors for oxygen-dependent proteolysis. Nature 1999;399:271-275.

29 Zhou J, Fandrey J, Schumann J, Tiegs G, Brune B: NO and TNF-alpha released from activated macrophages stabilize HIF-1alpha in resting tubular LLC-PK1 cells. Am J Physiol Cell Physiol 2003;284:C439-C446.

30 Sandau KB, Zhou J, Kietzmann T, Brune B: Regulation of the hypoxia-inducible factor 1alpha by the inflammatory mediators nitric oxide and tumor necrosis factor-alpha in contrast to desferroxamine and phenylarsine oxide. $\mathrm{J}$ Biol Chem 2001;276:39805-39811.

31 Prass K, Ruscher K, Karsch M, Isaev N, Megow D, Priller J, Scharff A, Dirnagl U, Meisel A: Desferrioxamine induces delayed tolerance against cerebral ischemia in vivo and in vitro. $\mathrm{J}$ Cereb Blood Flow Metab 2002;22:520-525.

32 Furuta GT, Turner JR, Taylor CT, Hershberg RM, Comerford K, Narravula S, Podolsky DK, Colgan SP: Hypoxia-inducible factor 1-dependent induction of intestinal trefoil factor protects barrier function during hypoxia. J Exp Med 2001;193:1027-1034.

33 Matsumoto M, Makino Y, Tanaka T, Tanaka H, Ishizaka N, Noiri E, Fujita T, Nangaku M: Induction of renoprotective gene expression by cobalt ameliorates ischemic injury of the kidney in rats. J Am Soc Nephrol 2003;14:18251832. 